\title{
New nomenclature for robotic-assisted thoracic surgery also gets rid of RATS
}

\author{
Abbas E. Abbas, MD, MS, FACS \\ From the Division of Thoracic Surgery, Department of Thoracic Medicine and Surgery, Temple University Health \\ System, Lewis Katz School of Medicine at Temple University, Philadelphia, Pa. \\ Disclosures: Author has nothing to disclose with regard to commercial support. \\ Received for publication March 21, 2017; accepted for publication March 21, 2017; available ahead of print April \\ $19,2017$. \\ Address for reprints: Abbas E. Abbas, MD, MS, FACS, Division of Thoracic Surgery, Department of Thoracic \\ Medicine and Surgery, Temple University Health System, Lewis Katz School of Medicine, 3401 N Broad \\ St, Suite C-100, Philadelphia, PA 19035 (E-mail: abbas.abbas@temple.edu). \\ J Thorac Cardiovasc Surg 2017;154:1070-1 \\ $0022-5223 / \$ 36.00$ \\ Copyright (c) 2017 by The American Association for Thoracic Surgery \\ http://dx.doi.org/10.1016/j.jtcvs.2017.03.077
}

The names video-assisted thoracic surgery (VATS) and robotic-assisted thoracoscopic surgery (RATS) have been used to describe minimally invasive thoracic procedures. With the evolution of technology, technique, and temerity, surgeons adopted VATS for increasingly advanced procedures, including lobectomy. Such procedures were found not only to be feasible, but also associated with better outcomes. ${ }^{1-5}$ As a response, surgeons were keen to claim this new operation, but thoracoscopy sans rib spreading ${ }^{6,7}$ is not the only technique described as VATS. Even if an endoscope is used only for illumination or occasional viewing, the same name, VATS may be used.

As RATS appeared on the scene, this name also began to be used to describe any operation where a robot is used. Some perform the operation completely through ports. Others make a utility incision through which an assistant has both visual and manual access to the field. Yet others may use the robot for some of the procedure and VATS or thoracotomy for the rest, so-called hybrid procedures.

So why does it matter? Why not allow surgeons to describe their procedures as they wish? After all, they are all indeed robot-assisted. Ultimately, it is about the ability to clearly describe how we do a surgical procedure. There is a need for transparency on our part to meet the increasing scrutiny by patients, other specialties, and regulatory bodies. With this purpose, the American Association of Thoracic Surgeons Guideline Committee appointed a group to propose a definition and nomenclature system for robotic-assisted thoracic procedures. The Committee members, Drs Cerfolio, Louie, Farivar, Onaitis, and Park, are all accomplished RATS surgeons and courageously took on the difficult task of attempting to describe the enormously complex variety in techniques and procedures performed in thoracic surgery.

Proposed is a 4-unit system where $\mathrm{R}$ is for robot and $\mathrm{P}$ is for completely portal or $\mathrm{A}$ is for assisted (through utility incision). The next portion is an abbreviation for the procedure performed, and the final element is the number of robotic arms. Under this system, for example, a robotic

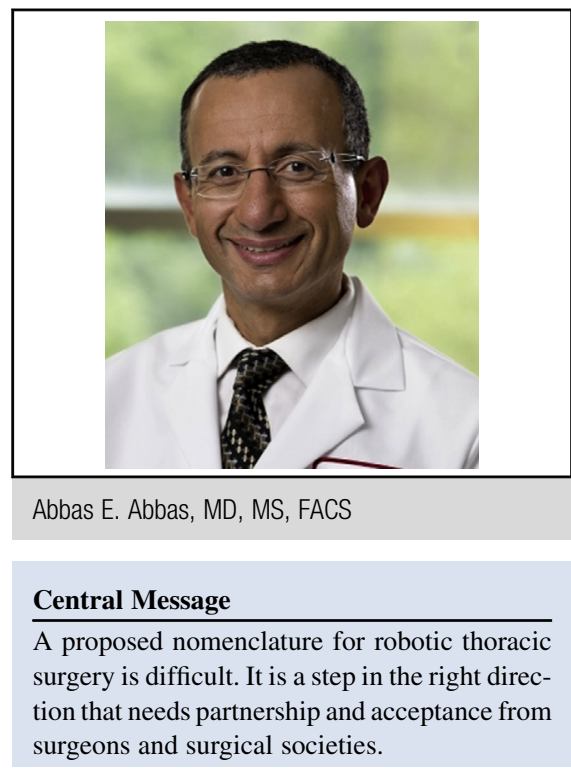

See Article page 1065 .

lobectomy would be named RPL(3or4), or RAL(3or4). When a nonrib spreading "extraction" incision is made at the end of the operation the operation is robotic portal, but if the same incision was made at the start, it is robotassisted. Some surgeons make a small incision early as security in the event of vascular injury but will only use it to remove a specimen. They may be discouraged from doing so to meet the perceived loftier definition of portal surgery. Perhaps we should instead describe these procedures as totally portal versus partially portal depending on whether the incision was actually utilized for nonportal assistance.

Can 1 system neatly pigeonhole all robotic procedures on the lung, pleura, chest wall, mediastinum, esophagus, and stomach? The authors wisely chose to focus only on lung and mediastinal procedures. The final product is quite elegant and certainly a step in the right direction. However, for this to work, surgeons must be persuaded to change what they call their own operations. Also, other thoracic and minimally invasive societies will have to support this nomenclature, which if ultimately adopted, would be in the name of science, not simplicity. One thing is certain: It would mark the end of RATS!

\section{References}

1. Landreneau RJ, Hazelrigg SR, Mack MJ, Dowling RD, Burke D, Gavlick J, et al Postoperative pain-related morbidity: video-assisted thoracic surgery versus thoracotomy. Ann Thorac Surg. 1993;56:1285-9. 
2. Jaklitsch MT, DeCamp MM Jr, Liptay MJ, Harpole DH Jr, Swanson SJ, Mentzer SJ, et al. Video-assisted thoracic surgery in the elderly. A review of 307 cases. Chest. 1996;110:751-8.

3. Demmy TL, Curtis JJ. Minimally invasive lobectomy directed toward frail and high-risk patients: a case-control study. Ann Thorac Surg. 1999;68: 194-200.

4. Kaseda S, Aoki T, Hangai N, Shimizu K. Better pulmonary function and prognosis with video-assisted thoracic surgery than with thoracotomy. Ann Thorac Surg. 2000;70:1644-6.
5. McKenna RJ Jr, Houck W, Fuller CB. Video-assisted thoracic surgery lobectomy: Experience with 1,100 cases. Ann Thorac Surg. 2006;81:421-5.

6. Swanson SJ, Herndon JE 2nd, D'Amico TA, Demmy TL, McKenna RJ Jr, Green MR, et al. Video-assisted thoracic surgery lobectomy: report of CALGB 39802 - a prospective, multi-institution feasibility study. J Clin Oncol. 2007;25: 4993-7.

7. Yan TD, Cao C, D'Amico TA, Demmy TL, He J, Hansen H, et al. Video-assisted thoracoscopic surgery lobectomy at 20 years: a consensus statement. Eur J Cardiothorac Surg. 2014;45:633-9. 